\title{
The efficacy of pulsatile gonadotropin-releasing hormone therapy in male patients with hypogonadism caused by hypopituitarism
}

\author{
Yulin Gu ${ }^{1 \#}$, Saichun Zhang ${ }^{1 \#}$, Xin $\mathrm{Li}^{2}$, Jingtao Dou ${ }^{1}$, Zhaohui Lyu ${ }^{1}$, Jianming $\mathrm{Ba}^{1}$, Qinghua Guo ${ }^{1}$, \\ Li Zang ${ }^{1}$, Kang Chen ${ }^{1}$, Jin Du ${ }^{1}$, Yu Pei ${ }^{1}$, Yiming Mu ${ }^{1}$, Weijun Gu ${ }^{1}$ \\ ${ }^{1}$ Department of Endocrinology, Medical School of Chinese People's Liberation Army, The First Medical Center of Chinese People's Liberation \\ Army General Hospital, Beijing, China; ${ }^{2}$ Department of Quality Management, Medical School of Chinese People's Liberation Army, The First \\ Medical Center of Chinese People's Liberation Army General Hospital, Beijing, China \\ Contributions: (I) Conception and design: W Gu; (II) Administrative support: Y Mu; (III) Provision of study materials or patients: J Dou, Z Lyu, J \\ Ba, Q Guo, L Zang, K Chen, J Du, Y Pei; (IV) Collection and assembly of data: Y Gu, S Zhang, X Li; (V) Data analysis and interpretation: Y Gu, S \\ Zhang; (VI) Manuscript writing: All authors; (VII) Final approval of manuscript: All authors. \\ "These authors contributed equally to this work. \\ Correspondence to: Weijun Gu; Yiming Mu. Department of Endocrinology, Medical School of Chinese People's Liberation Army, The First Medical \\ Center of Chinese People’s Liberation Army General Hospital, Beijing, China. Email: guweijun301@163.com; muyiming@301hospital.com.cn.
}

Backgroundt To evaluate the efficacy of pulsatile gonadotropin-releasing hormone (GnRH) therapy in patients with hypogonadism caused by hypopituitarism so as to guide clinical treatment.

Methods: Clinical manifestations, laboratory examinations, and imaging features were collected from 22 patients with hypopituitarism that led to hypogonadism who were treated with pulsatile GnRH. Data were analyzed and the patients were followed up.

Results: The average age at which patients began to use pulsatile GnRH was $22.8 \pm 3.7$ years old.

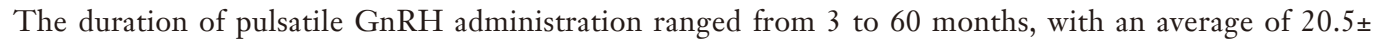
12.1 months. The dosage of GnRH administered was 10-12 $\mu \mathrm{g} / 90$ minutes. Patients were followed up for 26-81 months, with an average of 50.5 \pm 17.3 months. After pulsatile GnRH treatment, the clinical manifestations and hormone levels of these patients improved to varying degrees. The luteinizing hormone (LH) and testosterone (T) levels of 7 patients increased to the normal range, sperm could be detected in seminal fluid samples of 5 patients, and 2 patients successfully reproduced. Within the good-response group, $71.4 \%$ of patients achieved spermatogenesis within an average of 13 months of treatment. In patients who had poor response to gonadotropin therapy prior to pulsatile GnRH therapy, 25\% achieved spermatogenesis, and $37.5 \%$ reached the normal range of $\mathrm{LH}$ and $\mathrm{T}$. The levels of $\mathrm{LH}$ after pulsatile $\mathrm{GnRH}$ treatment was positively correlated with the peak levels of $\mathrm{LH}$ and testicular volume prior to treatment $(\mathrm{P}<0.01)$.

Conclusions: Pulsatile GnRH therapy can improve gonadal function in most patients with hypogonadism caused by hypopituitarism. Patients were able to achieve spermatogenesis, especially in patients who were poor-responders to gonadotropin treatment. Patients with greater basal testicular volume may respond better to pulsatile GnRH treatment. The GnRH stimulation test not only helps to evaluate the reserve function of pituitary GnRH cells at a certain time but may also serve as a prognostic factor. The results of this study form a basis for guiding clinical therapeutic choices.

Keywords: Hypogonadism; hypopituitarism; pulsatile gonadotropin-releasing hormone (pulsatile GnRH)

Submitted Feb 09, 2021. Accepted for publication Apr 17, 2021.

doi: 10.21037/apm-21-556

View this article at: http://dx.doi.org/10.21037/apm-21-556 


\section{Introduction}

Hypogonadism is a gonadal disease characterized by delayed development of the sexual organs and other secondary sex characteristics. It can be divided into primary hypogonadism and secondary hypogonadism. Hypopituitarism is a common cause of secondary hypogonadism. It is the partial or complete insufficiency of anterior pituitary hormone secretion and may result from pituitary or hypothalamic disease. Gonadotropin deficiency occurs in approximately $76.9 \%$ to $100 \%$ of patients with hypopituitarism (1-3). The clinical manifestation of patients with gonadotropin deficiency is delayed puberty or hypogonadism, which includes the absence of developed genitals, small testicles, and the absence of pubic hair and axillary hair. In patients with hypogonadism that is caused by hypopituitarism, treatment may be initiated for two purposes, that being androgenization and fertility (4). The former can be achieved by testosterone (T) substitution, and the latter can be achieved by treatment with gonadotropins or pulsatile gonadotropin-releasing hormone (GnRH) $(5,6)$.

Pulsatile GnRH treatments are dispensed via a portable pump with a subcutaneous needle inserted into the abdominal wall. It stimulates the production of luteinizing hormone (LH) and follicle-stimulating hormone (FSH) (7). Pulsatile administration of $\mathrm{GnRH}$ is effective in activating the pituitary-gonadal axis (8). Recently, some studies suggested that pulsatile GnRH therapy can be successfully used to induce puberty in hypogonadotropic hypogonadisms $(\mathrm{HH})$, and can reduce the risk of ovarian hyperstimulation syndrome in patients treated for $\mathrm{HH}$ (9-11). This current study examined the therapeutic effects of pulsatile GnRH therapy in male patients with hypogonadism caused by anterior pituitary dysfunction. The clinical experience in our department is summarized to form a basis for the development of novel treatment methods.

The clinical data of 22 patients were retrospectively analyzed in the Department of Endocrinology of the First Medical Center of the Chinese People's Liberation Army General Hospital. Following treatment with pulsatile GnRH therapy, the clinical manifestations and hormone levels in these patients improved to varying degrees. The $\mathrm{LH}$ and $\mathrm{T}$ levels of 7 patients increased to the normal range, sperm could be detected in the seminal fluid samples of 5 patients, and 2 patients successfully reproduced offspring. Within the good-response group of patients, a total of $71.4 \%$ achieved spermatogenesis. In patients with poor response to gonadotropin therapy, pulsatile GnRH therapy results in spermatogenesis in 25\% of patients, and $37.5 \%$ of patients reached the normal range of $\mathrm{LH}$ and $\mathrm{T}$.

We present the following article in accordance with the STROBE reporting checklist (available at http://dx.doi. org/10.21037/apm-21-556).

\section{Methods}

\section{Patient selection}

A total of 22 patients with hypopituitarism and hypogonadism were recruited at the Department of Endocrinology of the First Medical Center of the Chinese People's Liberation Army General Hospital between June 2012 and June 2017. The study size was calculated. The inclusion criteria were as follows: (I) patients older than 16 years of age; (II) absent or incomplete pubertal development with low serum T levels during childhood; (III) secondary hypogonadism, with deficiencies in at least two anterior pituitary hormones; and (IV) gonadotropin deficiencies or low-level results on the growth hormone (GH) stimulation test. The following exclusion criteria were applied: (I) severe systematic disease; and (II) T replacement therapy within the past 6 weeks or gonadotropin injection within the past 6 months.

\section{Clinical data and functional evaluation}

Clinical information was collected from patients, including general information, clinical manifestations, birth history, family history, past history, past medication history, physical examination, and laboratory examination. All investigators were trained with standard method about asking medical history before carrying out the study.

Anterior pituitary function was evaluated in all patients at the time of first admission to the hospital and was repeated, if necessary, during follow-up. To assess GH secretion, basal GH and insulin-like growth factor 1 (IGF-1) levels were measured, and insulin-induced hypoglycemic GH stimulation tests were performed. A peak GH level less than $10 \mu \mathrm{g} / \mathrm{L}$ after stimulation implied GH deficiency. To examine the pituitary-gonadal axis, basal LH, FSH, and T levels were measured, and GnRH stimulation tests were performed. To asses the pituitarythyroid axis, free triiodothyronine (FT3), free thyroxine 
(FT4), total triiodothyronine (TT3), total thyroxine (TT4), and thyroid stimulating hormone (TSH) levels were evaluated. To examine the pituitary-adrenal axis, cortisol, and adrenocorticotropic hormone (ACTH) levels were measured at 12:00 am, 8:00 am, and 4:00 pm. Urine was collected over a 24 hour period to measure free cortisol levels. Furthermore, insulin-induced hypoglycemic stimulation tests were performed to analyze any decrease in pituitary ACTH reserve function. The abovementioned study variables were measured using a automatic biochemical analyzer (Hitachi, Tokyo, Japan).

\section{Medical imaging}

Medical imaging was performed to collect baseline data prior to pulsatile GnRH treatment. Pituitary magnetic resonance imaging (MRI) scans were performed to understand the development of the pituitary. The $\mathrm{X}$ scan of the left wrist was used to determine the age of the bone and the osteophyte closure. Testicular volume was measured using ultrasound.

\section{Pulsatile GnRH treatment}

Pulsatile GnRH was administered subcutaneously via a portable infusion pump. The GnRH dose was initiated at $10 \mu \mathrm{g} / 90$ minutes and adjusted according to the serum LH, $\mathrm{FSH}$, and T levels. The maximum GnRH dose was set at $12 \mu \mathrm{g} / 90$ minutes.

\section{Follow-up}

All patients were followed-up every 3 months to measure testicular volume, LH levels, FSH levels, T levels, sperm count, and the development of secondary sexual characteristics. The follow-up ends when they no longer use the pulsatile GnRH treatment or lost to follow-up. Quantitative variables were recorded according to the patients description.

\section{Ethical statement}

This study was approved by the ethics committee of the Chinese People's Liberation Army General Hospital (No. S2017-131-02). Informed consent was obtained from all patients. All procedures performed in studies involving human participants were in accordance with the Declaration of Helsinki (as revised in 2013).

\section{Statistical analysis}

All statistical analyses were performed using SPSS version 21 (Microsoft). The normally distributed data were described by mean \pm standard deviation $(\bar{x} \pm s)$, and data with a skewed distribution were described by the mean $(\mathrm{M})$ and interquartile range $\left(Q_{1}, Q_{3}\right)$. For comparison of the baseline and post-treatment measurements, paired $t$-tests were used for normally distributed data, and nonparametric pairwise tests were used for data with skewed distributions. The Spearman's rank correlation coefficient was applied for correlation analyses. Results were considered statistically significant when $\mathrm{P}<0.05$.

\section{Results}

\section{Characteristics of the patients}

In total, 22 patients were enrolled in this study. The age at which patients commenced pulsatile GnRH therapy ranged from 16 to 33 years old, with an average age of $22.8 \pm 3.7$ years. All patients presented with varying degrees of hypogonadism. The majority were initially referred for growth retardation during childhood with no spontaneous pubertal development. One patient presented with loss of beard, armpit hair, and pubic hair, and sexual dysfunction after a craniopharyngioma operation. One patient suffered from pituitary microadenoma. All patients were azoospermic. There were 17 cases of patients suffering from adverse perinatal events ( 1 case of premature birth, 7 cases of footling presentation, 5 cases of breech presentation, 11 cases of dystocia and history of asphyxia, and 1 case of a history of birth canal extrusion). Three patients had a maternal history of medication use during pregnancy (including epilepsy drugs, antibiotics, and Chinese medicine) and one patient had a maternal history of fertilizer exposure.

\section{Hormone deficiency}

Within the study cohort, $77 \%$ of patients suffered from adrenocortical insufficiency, and 8 patients were treated with glucocorticoids. A total of 14 patients suffered from thyroid deficiency, and 10 patients had been treated with thyroid hormone. Growth hormone deficiency was detected in 19 patients, and 15 patients had been administered GH (Table 1). A total of 8 patients were treated with gonadotropin in other hospitals prior to receiving pulsatile GnRH therapy, and 9 patients had received $\mathrm{T}$ replacement 
Table 1 The characteristics and medical history of 22 patients

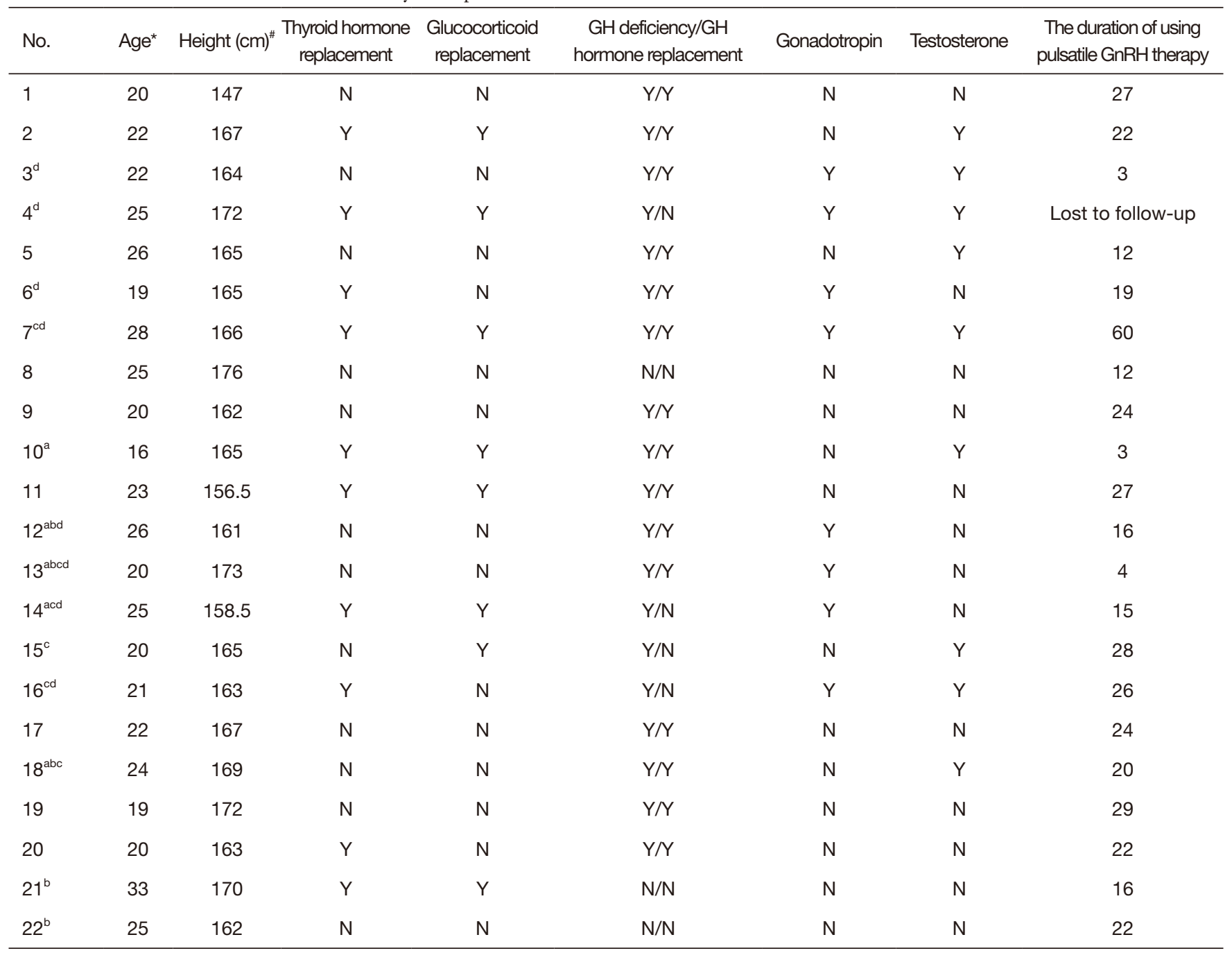

*, patient age at the commencement of pulsatile gonadotropin-releasing hormone (GnRH) therapy; , patient height at the commencement of pulsatile GnRH therapy. " , achieved normal levels of leuteinizing hormone (LH) and testosterone (T) after treatment with pulsatile GnRH therapy; ${ }^{b}$, Achieved the presence of sperm; ${ }^{c}$, continued using pulsatile $\mathrm{GnRH}$ therapy until follow-up; ${ }^{\mathrm{d}}$, patients who had poor response to prior gonadotropin treatment before admission to hospital. Y, yes; N, no; GH, growth hormone.

therapy prior to admission to our hospital (Table 1).

\section{Medical images}

A total of 22 patients underwent pituitary MRI scans with dynamic enhancement. The MRI revealed 19 cases of patients with small anterior pituitaries, ectopic posterior pituitary bright spots, and absence of the pituitary stalk or a thin pituitary stalk ( 1 case presented with a Chiari-I malformation with syringomyelia, 1 case had an arachnoid cyst of the cisterna magna, and 2 cases presented with partially empty sella). One patient had a craniopharyngioma and one patient presented with pituitary microadenomas. There was only one case with a normal pituitary gland.

Testicular ultrasound showed that the testicular volume of 18 patients was less than $3 \mathrm{~mL}$. One patient presented with cryptorchidism. The bone age of all the patients lagged significantly behind their actual age.

\section{Response to pulsatile GnRH therapy}

All 22 patients were treated with pulsatile $\mathrm{GnRH}$ at 
Table 2 A comparison of hormone levels, testicular volume, penis length, and spermatogenesis in the whole study cohort before and after pulsatile gonadotropin-releasing hormone therapy

\begin{tabular}{|c|c|c|c|}
\hline Parameter & Before & After & $P$ value \\
\hline $\mathrm{LH}(\mathrm{mlU} / \mathrm{mL})$ & $0.07(0.07,1.28)$ & $1.43(0.07,5.03)$ & $0.034^{\oplus}$ \\
\hline FSH (IU/L) & $0.92(0.30,1.88)$ & $2.46(0.88,4.67)$ & $0.029^{\circledR}$ \\
\hline $\mathrm{T}(\mathrm{nmol} / \mathrm{L})$ & $0.53(0.35,0.91)$ & $2.99(0.91,7.23)$ & $0.001^{@}$ \\
\hline Testicular volume (mL) & $0.75(0.48,1.48)$ & $2.60(1.23,4.98)$ & $<0.001^{@}$ \\
\hline Spermatogenesis $(\%, n / n)$ & 0 & $22.73 \%(5 / 22)$ & - \\
\hline Rate of normal levels of LH and $T(\%, n / n)$ & 0 & $22.73 \%(5 / 22)$ & - \\
\hline
\end{tabular}

Normal range: FSH 1.27-19.26 IU/L, LH 1.24-8.62 mlU/mL, T 6.07-27.1 nmol/L. ${ }^{\circledR}$ represents $\mathrm{P}<0.05$, where $\mathrm{P}<0.05$ indicates statistically significant differences. $\mathrm{LH}$, luteinizing hormone; $\mathrm{FSH}$, follicle-stimulating hormone; T, testosterone.

Table 3 The correlation coefficients among different parameters

\begin{tabular}{lccc}
\hline Parameter & $\begin{array}{c}\text { Peak level of LH before the } \\
\text { treatment }\end{array}$ & $\begin{array}{c}\text { Average testicular volume } \\
\text { before treatment }\end{array}$ & LH levels after treatment \\
\hline Peak level of LH before the treatment & 1.00 & $0.849^{\circledR}$ & $0.775^{@}$ \\
Average testicular volume before treatment & - & 1.00 & $0.706^{@}$ \\
LH levels after treatment & - & - & 1.000 \\
\hline
\end{tabular}

${ }^{\circledR}$ represents $\mathrm{P}<0.01$, where $\mathrm{P}<0.05$ indicates statistically significant differences. $\mathrm{LH}$, luteinizing hormone.

$10 \mu \mathrm{g} / 90$ minute subcutaneously for 3 to 60 months, with an average of $20.5 \pm 12.1$ months. The follow-up period ranged from 26-81 months, with an average of 50.5 \pm 17.3 months. Case number 4 was lost to follow-up. During the treatment, the dosage for case number 14 was increased to $12 \mu \mathrm{g} / 90$ minutes to achieve a stronger effect, and subsequently decreased to $10 \mu \mathrm{g} / 90$ minutes until normal levels of LH and T were achieved. A total of 6 patients continued pulsatile GnRH therapy up until August 2019 (Table 1). The LH and T levels of 5 patients increased to the normal range (Table 2). Five patients achieved spermatogenesis after an average of 13 months of treatment, and 2 patients achieved reproductive success. Treatment with GnRH therapy increased the levels of $\mathrm{LH}, \mathrm{FSH}$, and T from $0.07(0.07,1.28) \mathrm{mIU} / \mathrm{mL}$ to $1.43(0.07,5.03) \mathrm{mIU} / \mathrm{mL}$ $(\mathrm{P}=0.034)$, from $0.92(0.30,1.88) \mathrm{IU} / \mathrm{L}$ to $2.46(0.88$, 4.67) IU/L ( $\mathrm{P}=0.029)$, and from $0.53(0.35,0.91) \mathrm{nmol} / \mathrm{L}$ to $2.99(0.91,7.23) \mathrm{nmol} / \mathrm{L}(\mathrm{P}=0.001)$, respectively. Testicular volume increased from $0.75(0.48,1.48) \mathrm{mL}$ to $2.60(1.23,4.98) \mathrm{mL}(\mathrm{P}<0.001)$ after pulsatile $\mathrm{GnRH}$ treatment. The length of the penis was also increased from $3.45 \pm 1.35$ to $7.59 \pm 3.57 \mathrm{~cm}(\mathrm{P}<0.001)$ following pulsatile
GnRH treatment. In addition, 10 patients had pubic hair growth, 7 patients had mane growth, 10 patients had erections, 4 patients had spermatorrhea, and 8 patients had beard growth, larynx growth, and voice changes. Suprisingly, after using pulsatile GnRH therapy, the LH levels of 4 patients increased to normal, but subsequently decreased for different durations.

The LH levels following pulsatile GnRH therapy were positively correlated with the basal testicular volume (correlation coefficient $0.706, \mathrm{P}<0.01$ ) and the peak level of LH before the treatment (correlation coefficient $0.775, \mathrm{P}<0.01)$. Moreover, the peak level of LH before the treatment was also positively correlated with the basal testicular volume (correlation coefficient $0.849, \mathrm{P}<0.01$ ) (Table 3).

The patients were divided into two groups, the goodresponse group and the poor-response group. The goodresponse group included patients with a substantial increase in $\mathrm{T}$ and $\mathrm{LH}$ levels to levels within the normal range. Patients with no substantial increase in $\mathrm{T}$ and $\mathrm{LH}$ levels, with levels below the normal range were defined as the poor-response group. The duration of treatment, 
Table 4 A comparison of hormone levels, testicular volume, penis length, spermatogenesis, and treatment duration between the good-response group and the poor-response group

\begin{tabular}{|c|c|c|c|}
\hline Parameter & Good-response Group ( $n=7)$ & Poor-response Group ( $n=15)$ & $P$ value \\
\hline \multicolumn{4}{|l|}{ Baseline } \\
\hline $\mathrm{LH}(\mathrm{mlU} / \mathrm{mL})$ & $1.15(0.07,1.91)$ & $0.07(0.07,0.08)$ & $0.020^{@}$ \\
\hline FSH (IU/L) & $1.83(0.79,2.56)$ & $0.47(0.30,1.09)$ & 0.108 \\
\hline Testicular volume $(\mathrm{mL})$ & $1.70(1.19,4.49)$ & $0.68(0.45,0.88)$ & $0.021^{\circledR}$ \\
\hline The length of penis $(\mathrm{cm})$ & $3.71 \pm 0.95$ & $3.72 \pm 1.69$ & 0.984 \\
\hline \multicolumn{4}{|l|}{ After pulsatile GnRH treatment } \\
\hline $\mathrm{LH}(\mathrm{mlU} / \mathrm{mL})$ & $5.62(3.90,9.81)$ & $0.07(0.07,1.28)$ & $0.001^{\circledR}$ \\
\hline Testicular volume $(\mathrm{mL})$ & $5.75(4.98,7.10)$ & $2.05(1.03,3.45)$ & $0.001^{\circledR}$ \\
\hline The length of penis $(\mathrm{cm})$ & $10.58 \pm 2.33$ & $5.91 \pm 2.82$ & $0.004^{@}$ \\
\hline Spermatogenesis $(\%, n / n)$ & $71.43 \%(5 / 7)$ & 0 & - \\
\hline $\begin{array}{l}\text { Patients who reached normal levels of } \mathrm{LH} \text { and } \mathrm{T} \\
(\%, \mathrm{n} / \mathrm{n})\end{array}$ & $71.43 \%(5 / 7)$ & 0 & - \\
\hline
\end{tabular}

Normal range: FSH 1.27-19.26 IU/L, LH 1.24-8.62 mIU/mL, T 6.07-27.1 nmol/L. ${ }^{\circledR}$ represents $\mathrm{P}<0.05$, where $\mathrm{P}<0.05$ indicates statistically significant differences. LH, luteinizing hormone; FSH, follicle-stimulating hormone; T, testosterone; GnRH, gonadotropin-releasing hormone.

hormone levels, testicular volume, and spermatogenesis were compared between the two groups. As shown in Table 4, the duration of treatment in the good-response group was $13.7 \pm 7.4$ months, while the duration of treatment for the poor-response group was $23.9 \pm 12.8$ months $(\mathrm{P}=0.032)$. At baseline, the levels of $\mathrm{LH}$ were significantly higher in the good-response group compared to the poorresponse group $[1.15(0.07,1.91) \mathrm{mIU} / \mathrm{mL}$ vs. $0.07(0.07$, $0.08) \mathrm{mIU} / \mathrm{mL} ; \mathrm{P}=0.020]$ and the volume of the testes was significantly greater in the good-response group [1.70 (1.19, 4.49) $\mathrm{mL}]$ compared to the poor-response group [0.68 (0.45, $0.88) \mathrm{mL} ; \mathrm{P}=0.021]$. However, the levels of FSH and T, and the length of the penis at baseline were not significantly different between the two groups. After treatment with GnRH, the levels of LH and T, the volume of the testes, and the length of the penis in the good-response group were significantly improved compared to the poor-response group (Table 4). Spermatogenesis was detected in $71.43 \%$ of the good-response group, and 5 patients reached the normal levels of $\mathrm{LH}$ and T. However, none of the patients in the poor-response group achieved spermatogenesis or the acceptable range of $\mathrm{LH}$ and $\mathrm{T}$.

In the study cohort of 22 patients, 8 patients had responded poorly to prior gonadotropin treatment. These patients with poor responses to gonadotropin were treated with pulsatile GnRH therapy, and the $\mathrm{LH}$ and T levels of 3 of these patients $(37.5 \%, 3 / 8)$ increased to the normal range. The average levels of $\mathrm{LH}$ increased from $0.11(0.07$, 1.39) $\mathrm{mIU} / \mathrm{mL}$ pre-treatment to $2.80(1.78,9.86) \mathrm{mIU} / \mathrm{mL}$ post-treatment $(\mathrm{P}=0.028)$. Similarly, the levels of FSH and $\mathrm{T}$ increased from $0.95(0.37,2.87) \mathrm{IU} / \mathrm{L}$ pre-treatment to $4.32(3.18,6.08) \mathrm{IU} / \mathrm{L}$ post-treatment $(\mathrm{P}=0.028)$, and from $0.53(0.35,2.03) \mathrm{nmol} / \mathrm{L}$ pre-treatment to $7.23(3.26$, $11.36) \mathrm{nmol} / \mathrm{L}$ post-treatment $(\mathrm{P}=0.028)$, respectively. Furthermore, the testicular volume increased by more than $4 \mathrm{~mL}$ in $62.5 \%$ of patients, and the average volume of the testes increased from $1.80(0.78,3.66) \mathrm{mL}$ to 4.55 (3.91, 6.11) $\mathrm{mL}(\mathrm{P}=0.025)$ after pulsatile $\mathrm{GnRH}$ treatment. The length of the penis also increased from $3.9 \pm 1.1$ to $8.8 \pm$ $3.6 \mathrm{~cm}(\mathrm{P}=0.009)$ post- pulsatile $\mathrm{GnRH}$ therapy. Moreover, 
Table 5 The efficacy of pulsatile gonadotropin-releasing hormone therapy among patients with poor response to gonadotropin therapy

\begin{tabular}{|c|c|c|c|}
\hline Parameter & Before GnRH pump treatment & After GnRH pump treatment & $P$ value \\
\hline FSH (IU/L) & $0.95(0.37,2.87)$ & $4.32(3.18,6.08)$ & $0.028^{@}$ \\
\hline $\mathrm{T}(\mathrm{nmol} / \mathrm{L})$ & $0.53(0.35,2.03)$ & $7.23(3.26,11.36)$ & $0.028^{@}$ \\
\hline Testicular volume $(\mathrm{mL})$ & $1.80(0.78,3.66)$ & $4.55(3.91,6.11)$ & $0.025^{\circledR}$ \\
\hline Spermatogenesis $(\%, n / n)$ & 0 & $25 \%(2 / 8)$ & - \\
\hline $\begin{array}{l}\text { Patients who reached normal levels of } \\
\text { LH and } T(\%, n / n)\end{array}$ & 0 & $37.5 \%(3 / 8)$ & - \\
\hline
\end{tabular}

Normal range: FSH 1.27-19.26 IU/L, LH 1.24-8.62 mIU/mL, T 6.07-27.1 nmol/L. ${ }^{\circledR}$ represents $\mathrm{P}<0.05$, where $\mathrm{P}<0.05$ indicates statistically significant differences. LH, luteinizing hormone; FSH, follicle-stimulating hormone; T, testosterone; GnRH, gondatropin-releasing hormone.

the presence of sperm could be detected in $25 \%(2 / 8)$ of these patients with poor gonadotropin response (Table 5).

\section{Adverse reactions due to pulsatile GnRH therapy}

Of the 22 patients who were followed up, 5 patients developed hard subcutaneous hard masses, 1 patient developed a rash, 5 patients had inflammation at the injection site, 1 patient suffered ulcers at the site of injection, and 2 patients had allergic reactions. Most of these patients stop using pulsatile GnRH therapy due to the inefficency, allergy inflammation at the injection site, rash, or inconvenience.

\section{Discussion}

This study demonstrated that $71.4 \%$ of patients in the good-response group had achieved spermatogenesis. Among patients with poor response to gonadotropin and T, $25 \%$ achieved spermatogenesis and $37.5 \%$ reached the normal range of $\mathrm{LH}$ and $\mathrm{T}$. This study demonstrated the effectiveness of pulsatile GnRH therapy in patients with hypogonadism caused by hypopituitarism.

The treatment of anterior pituitary dysfunction mainly involves supplementing the target gland with the appropriate hormone. For male patients with fertility requirements, human chorionic gonadotropin (hCG) and human menopausal gonadotropin (hMG) therapy can be administered (12-16). Previous studies have shown that pulsatile GnRH therapy is effective in inducing virilization and spermatogenesis in patients with isolated congenital $\mathrm{HH}$ (17). Moreover, some case reports have demonstrated the effectiveness of pulsatile GnRH therapy in patients with acquired hypopituitarism caused by pituitary tumor resection or cranial radiotherapy (18-20). As early as 1989, Professor $\mathrm{Lu}$ of our department reported that $\mathrm{GnRH}$ pulse therapy had a stimulating effect on pituitary gonadotropin cells in 10 patients with hypothalamic hypogonadism. Shao et al. (21) reported 2 cases of hypogonadism caused by pituitary stalk interruption syndrome. After 12 weeks of pulsatile GnRH treatment, the levels of FSH, LH, and $\mathrm{T}$ showed an upward trend, but the $\mathrm{T}$ value was still lower than normal. However, pulsatile GnRH therapy has been rarely reported for the treatment of patients with hypogonadism that is caused by hypopituitarism. In the present study, 22 such patients were treated with a pulsatile GnRH therapy for 3 to 60 months with subcutaneous pumps at $10 \mu \mathrm{g} / 90$ minutes to $12 \mu \mathrm{g} / 90$ minutes. After the treatment, the clinical manifestations of the patients showed varying degrees of improvement. Among the 22 patients, 7 reached the normal range of $\mathrm{LH}$ and $\mathrm{T}$ levels, sperm production was detected in 5 patients, and 2 patients achieved successful reproduction. The lack of success in achieving normalized $\mathrm{LH}$ and $\mathrm{T}$ levels in some patients may be due to years of alternative treatments without good outcomes and thus, the opportune time for pulsatile $\mathrm{GnRH}$ therapy may have been missed.

In the good-response group, the levels of LH, the volume of the testes, and the rate of patients who reached normal levels of $\mathrm{LH}$ and $\mathrm{T}$ were increased after the treatment with pulsatile GnRH, suggesting that anterior pituitary gonadotropic cells were still present. The results suggested that $\mathrm{T}$ increases tend to lag behind the increases seen in LH levels, which has been observed during the 
progression of normal pubertal development $(22,23)$. This phenomenon suggested that pulsatile $\mathrm{GnRH}$ therapy may mimic a pubertal developmental course and may reflect a more physiological therapy.

Considering the high costs associated with pulsatile $\mathrm{GnRH}$ therapy, is not an option for use in the general patient. However, for patients with poor responses to gonadotropin therapy, pulsatile GnRH therapy may be an excellent choice (24). As shown in this current study, following pulsatile GnRH therapy in patients with poor response to gonadotropin, the levels of $\mathrm{LH}, \mathrm{FSH}$, and $\mathrm{T}$ were significantly increased compared with the baseline data. The testicular volume and the length of the penis were also significantly increased. Spermatogenesis was detected in $25 \%$ of these patients, and $37.5 \%$ reached the normal levels of $\mathrm{LH}$ and $\mathrm{T}$. It is possible that there is a gonadotropic cell reserve in the pituitary gland which can respond to stimulation by pulsatile GnRH therapy (1). Pulsatile GnRH therapy may mimic a more physiological therapy compared to gonadotropin or T therapy. Furthermore, gonadotrophic cell regeneration from pluripotent stem cells may play an important role (25). The number of hormone-producing cells could change according to physiological demands.

The duration and efficacy of using pulsatile GnRH therapy varies in different study. Some research found that the length of time for sperm to appear after using pulsatile GnRH treatment ranged widely from 2-22 months (5). Most patients require at least 2 years to maximize testicular volume and achieve spermatogenesis, while patients with small testes will take even longer (26). It has been reported that $82 \%$ of patients achieved spermatogenesis after 24 months of treatment (27). In this study, $71.4 \%$ of patients in the goodresponse group achieved spermatogenesis after an average of 13 months of wearing the pump, and 2 patients successfully reproduced. Patients with a larger testicular volume and higher LH levels are likely to achieve better results. The rate of spermatogenesis in the present study is much higher than that observed in previous studies (1) and may be due to the longer duration of pulsatile GnRH therapy.

It is generally believed that testicular volume before treatment is one of the main factors affecting the prognosis of patients with $\mathrm{HH}(5,28,29)$. When the pre-treatment testicular volume is large $(>4 \mathrm{~mL})$ and the patients have already undergone a certain degree of puberty, the therapeutic effects of GnRH therapy are better. This study demonstrated that the LH levels after pulsatile GnRH treatment were positively correlated with the pre-treatment testicular volume. Patients with larger basal testicular volume were also more responsive to treatment (Table 5).

In addition, this study revealed that the peak level of LH was positively correlated with pre-treatment testicular volume and the LH levels after pulsatile GnRH therapy, suggesting that the GnRH stimulation test not only helps to evaluate the reserve function of the pituitary GnRH cells at a given time but may also be a prognostic factor for the outcome of treatment with pulsatile GnRH (16).

In this study, the levels of sex hormones in some patients returned to the normal range but then decreased again. This may be due to mutations in the GnRH receptor gene which may lead to the failure of pulsatile GnRH therapy (25). Moreover, if antibodies against $\mathrm{GnRH}$ or its receptor are produced during pulsatile GnRH treatment, it will also lead to failure (25). In addition, the normal secretion rhythm of GnRH may promote the secretion of sex hormones, while the continued secretion of GnRH may inhibit the secretion of gonadotropin and the function of the pituitarygonadal axis. Only physiological doses and frequencies can restore the sensitivity of the pituitary gland. Belchetz et al. (30) suggested that sustained GnRH stimulation may produce a "desensitization" or "down regulation" effect. Stanhope and colleagues (31) reported a case of a woman being administered pulsatile GnRH therapy (15 $\mu \mathrm{g} / 90$ minutes) to treat puberty retardation. She showed a significant increase in uterus size, ovary size, and the number of follicles during the first 2 months of treatment, but after 3 months, the uterus, ovary, and follicles gradually degenerated, without any growth after 7 months. The researchers suggested that this may be related to the fact that $15 \mu \mathrm{g} / 90$ minutes of $\mathrm{GnRH}$ is too much for the patient and caused "desensitization" of the pituitary gonadotropic cells. The observations of our current study suggests that close attention should be given to individual differences in responses to pulsatile GnRH therapy, and the frequency and dose of pulsatile GnRH treatment should be adjusted within a range that can activate the pituitary-gonadal axis. This is especially so for patients with secondary failure. Moreover, when pulsatile GnRH therapy fails, mutations in the GnRH receptor gene or the presence of antibodies against $\mathrm{GnRH}$ or its receptors should be considered.

There are some limitations to this study. First, the follow-up time was insufficient, and some data was lost. Second, most patients had been treated unsuccessfully with other options for many years prior to pulsatile GnRH therapy and the optimal time for treatment may have been missed. Third, the number of patients treated with pulsatile GnRH therapy in this study was limited and further large- 
scale, randomized, controlled clinical studies are needed to accumulate more clinical data.

\section{Conclusions}

In summary, the application of pulsatile GnRH therapy in patients with hypogonadism caused by anterior pituitary dysfunction increased LH levels, T levels, testes volume, and penis growth, and helped patients achieve spermatogenesis, especially among those who were poor responders to gonadotropin.

\section{Acknowledgments}

The authors thank all the patients at the First Medical Center of the Chinese People's Liberation Army General Hospital who formed part of the treatment groups.

Funding: None.

\section{Footnote}

Reporting Checklist: The authors have completed the STROBE reporting checklist. Available at http://dx.doi. org/10.21037/apm-21-556

Data Sharing Statement: Available at http://dx.doi. org/10.21037/apm-21-556

Conflicts of Interest: All authors have completed the ICMJE uniform disclosure form (available at http://dx.doi. org/10.21037/apm-21-556). The authors have no conflicts of interest to declare.

Ethical Statement: The authors are accountable for all aspects of the work in ensuring that questions related to the accuracy or integrity of any part of the work are appropriately investigated and resolved. This study was approved by the ethics committee of the Chinese People's Liberation Army General Hospital (No. S2017-13102). Informed consent was obtained from all patients. All procedures performed in studies involving human participants were in accordance with the Declaration of Helsinki (as revised in 2013).

Open Access Statement: This is an Open Access article distributed in accordance with the Creative Commons Attribution-NonCommercial-NoDerivs 4.0 International License (CC BY-NC-ND 4.0), which permits the non- commercial replication and distribution of the article with the strict proviso that no changes or edits are made and the original work is properly cited (including links to both the formal publication through the relevant DOI and the license). See: https://creativecommons.org/licenses/by-nc-nd/4.0/.

\section{References}

1. Zheng J, Mao J, Xu H, et al. Pulsatile GnRH Therapy May Restore Hypothalamus-Pituitary-Testis Axis Function in Patients With Congenital Combined Pituitary Hormone Deficiency: A Prospective, Self-Controlled Trial. J Clin Endocrinol Metab 2017;102:2291-300.

2. Guo Q, Yang $Y, M u ~ Y$, et al. Pituitary stalk interruption syndrome in Chinese people: clinical characteristic analysis of 55 cases. PLoS One 2013;8:e53579.

3. Rottembourg D, Linglart A, Adamsbaum C, et al. Gonadotrophic status in adolescents with pituitary stalk interruption syndrome. Clin Endocrinol (Oxf) 2008;69:105-11.

4. Mao J, Xu H, Wang X, et al. Congenital combined pituitary hormone deficiency patients have better responses to gonadotrophin-induced spermatogenesis than idiopathic hypogonadotropic hypogonadism patients. Hum Reprod 2015;30:2031-37.

5. Büchter D, Behre HM, Kliesch S, et al. Pulsatile GnRH or human chorionic gonadotropin/human menopausal gonadotropin as effective treatment for men with hypogonadotropic hypogonadism: a review of 42 cases. Eur J Endocrinol 1998;139:298-303.

6. Silveira LF, Latronico AC. Approach to the Patient With Hypogonadotropic Hypogonadism. J Clin Endocrinol Metab 2013;98:1781-8.

7. Tavaniotou A, Albano C, Smitz J, et al. Impact of ovarian stimulation on corpus luteum function and embryonic implantation. J Reprod Immunol 2002;55:123-30.

8. Orvieto R, Rabinson J, Meltzer S, et al. GnRH agonist versus GnRH antagonist in ovarian stimulation: is the emperor naked? Clin Exp Obstet Gynecol 2006;33:197-9.

9. Raivio T, Falardeau J, Dwyer A, et al. Reversal of idiopathic hypogonadotropic hypogonadism. $\mathrm{N}$ Engl J Med 2007;357:863-73.

10. Casper RF. Introduction: Gonadotropin-releasing hormone agonist triggering of final follicular maturation for in vitro fertilization. Fertil Steril 2015;103:865-6.

11. Mittelman-Smith MA, Wong AM, Kathiresan AS, et al. Classical and membrane-initiated estrogen signaling in an in vitro model of anterior hypothalamic kisspeptin 
neurons. Endocrinology 2015;156:2162-73.

12. Bistritzer T, Lunenfeld B, Passwell JH, et al. Hormonal therapy and pubertal development in boys with selective hypogonadotropic hypogonadism. Fertil Steril 1989;52:302-6.

13. Barrio R, de Luis D, Alonso M, et al. Induction of puberty with human chorionic gonadotropin and follicle-stimulating hormone in adolescent males with hypogonadotropic hypogonadism. Fertil Steril 1999;71:244-8.

14. Zacharin M, Sabin MA, Nair VV, et al. Addition of recombinant follicle-stimulating hormone to human chorionic gonadotropin treatment in adolescents and young adults with hypogonadotropic hypogonadism promotes normal testicular growth and may promote early spermatogenesis. Fertil Steril 2012;98:836-42.

15. Sinisi AA, Esposito D, Maione L, et al. Seminal antiMüllerian hormone level is a marker of spermatogenic response during long-term gonadotropin therapy in male hypogonadotropic hypogonadism. Hum Reprod 2008;23:1029-34.

16. Rohayem J, Hauffa BP, Zacharin M, et al. Testicular growth and spermatogenesis: new goals for pubertal hormone replacement in boys with hypogonadotropic hypogonadism? - a multicenter prospective study of hCG/rFSH treatment outcomes during adolescence. Clin Endocrinol (Oxf) 2017;86:75-87.

17. Young J, Xu C, Papadakis GE, et al. Clinical Management of Congenital Hypogonadotropic Hypogonadism. Endocr Rev 2019;40:669-710.

18. Skarin G, Nillius SJ, Ahlsten G, et al. Induction of male puberty by long-term pulsatile subcutaneous LH-RH therapy. Ups J Med Sci 1984;89:73-80.

19. Partsch CJ, Sippell WG. Short-tem pulsatile administration of luteinizing hormone releasing hormone in male adolescents with multiple idiopathic pituitary hormone deficiencies. Horm Res 1987;25:88-96.

20. Pitteloud N, Hayes FJ, Dwyer A, et al. Predictor of outcome of long-term GnRH therapy in men with idiopathic hypogonadotropic hypogonadism. J Clin Endocrinol Metab 2002;87:4128-36.

21. Shao WM, Bai WJ, Chen YM, et al. Analysis of using gonadalin through microinjection to treat patients with hypogonadism caused by pituitary stalk interruption syndrome and literature review. J Peking University (Medical Sciences) 2014;46:642-5.

22. Albertsson-Wikland K, Rosberg S, Lannering B, et al. Twenty-four-hour profiles of luteinizing hormone, follicle- stimulating hormone, testosterone, and estradiol levels: a semilongitudinal study throughout puberty in healthy boys. J Clin Endocrinol Metab 1997;82:541-9.

23. Goji K, Tanikaze S. Spontaneous gonadotropin and testosterone concentration profiles in prepubertal and pubertal boys: temporal relationship between luteinizing hormone and testosterone. Pediatr Res 1993;34:229-36.

24. Delemarre-Van de Waal HA. Induction of testicular growth and spermatogenesis by pulsatile, intravenous administration of gonadotrophin-releasing hormone in patients with hypogonadotrophic hypogonadism. Clin Endocrinol (Oxf) 1993;38:473-80.

25. Ozone C, Suga H, Eiraku M, et al. Functional anterior pituitary generated in self-organizing culture of human enbryonic stem cells. Nat Commun 2016;7:10351.

26. Paola Ascoli, Francesco Cavagnini. Hypopituitarism. Pituitary 2006;9:335-42.

27. Pitteloud N, Hayes FJ, Dwyer A, et al. Predictors of outcome of long-term GnRH therapy in men with idiopathic hypogonadotropic hypogonadism. J Clin Endocrinol Metab 2002;87:4128-36.

28. Burris AS, Rodbard HW, Winters SJ, et al. Gonadotropin therapy in men with isolated hypogonadotropic hypogonadism: the response to human chorionic gonadotropin is predicted by initial testicular size. J Clin Endocrinol Metab 1988;66:1144-51.

29. Schopohl J,Mehltretter G,von Zumbusch R, et al. Comparison of gonadotropinreleasing hormone and gonadotropin therapy in male patients with idiopathic hypothalamic hypogonadism. Fertil Steril 1991, 56:1143-50.

30. Belchetz PE, Plant TM, Nakai Y, et al. Hypophysial responses to continuous and intermittent delivery of hypothalamic gonadotropin-releasing hormone. Science 1978;202:631-3.

31. Stanhope R, Abdulwahid NA, Adams J, et al. Problems in the use of pulsatile gonadotrphin-releasing hormone for the induction of puberty. Horm Res 1985;22:74-7.

(English Language Editor: J. Teoh)

Cite this article as: Gu Y, Zhang S, Li X, Dou J, Lyu Z, Ba J, Guo Q, Zang L, Chen K, Du J, Pei Y, Mu Y, Gu W. The efficacy of pulsatile gonadotropin-releasing hormone therapy in male patients with hypogonadism caused by hypopituitarism. Ann Palliat Med 2021;10(4):4642-4651. doi: 10.21037/apm-21556 